\begin{tabular}{ll} 
IJEMR & International Journal of \\
\hline & Emerging Multidisciplinary Research
\end{tabular}

\title{
A Research on the Importance of Labor Education Course in the Construction of Double-Class Universities in China
}

\author{
Jiang Jialei ${ }^{*}$ \\ ${ }^{1}$ School of Management, Xuzhou University of Technology, Xuzhou, Jiangsu, 221018, China
}

\begin{abstract}
Background/Objectives: This study analyzes the equity of the per capita investment scale of students in Korea. Methods/Statistical analysis: To conduct questionnaires and interviews with college students, teachers and parents, to listen to the opinions and suggestions of teachers and students on the labor education curriculum. Findings: Labour education is the training function of labour and the educational activities of young people who love and love labour. Labour education is a new requirement of the New Age Party for education, an important part of the socialist education system with Chinese characteristics, an important part of the overall development of the education system, and an educational activity that must be carried out realization in primary and secondary schools. It is important for the construction of Double-Class Universities in China. Improvements/Applications: In the present curriculum system of China, the education of the five kinds of moral, intellectual, physical, aesthetic and labor is uneven, and the curriculum of labor education is not paid attention. It is especially important to design a local curriculum suitable for the young people.
\end{abstract}

\section{Index Terms}

Labour Education, Curriculum, Curriculum system, Socialist education system, Double-Class Universities

\author{
Corresponding author : Jiang Jialei \\ jiangjialei@xzit.edu.cn \\ - Manuscript received March 2, 2021. \\ - Revised March 27, 2021; Accepted April 19, 2021. \\ - Date of publication June 30, 2021. \\ ๑) The Academic Society of Convergence Science Inc. \\ 2546-1583 @ 2017 IJEMR. Personal use is permitted, but republication/redistribution requires IJEMR permission.
}




\section{INTRODUCTION}

Labor is the essential characteristic of human beings, labor is the foundation of social development, labor education is the education of young people who love labour and love it. In 1953-1957, the state carried out a second curriculum reform, and for the first time set up a labor technology education course in a teaching plan[1].

The Labor Technology Education Course is the forerunner of the Labor Education Course, which includes the training of students' views on labor and their working habits so that students can master some of their skills. Over the past 60 years, it has not been properly standardized and implemented.

Taking advantage of the publication opportunity of "Advice on Comprehensive Strengthening the Work Education of Primary and Secondary Schools in the New Era", all local colleges and universities have reexamined the labor education system and tried to design the curriculum system according to local conditions.

The 14th Five-Year Plan for National Economic and Social Development and the vision for the future of 1935 proposed the establishment of a high-quality education system. We should comprehensively carry out the Party's educational policy, adhere to the principle of "strengthening the moral and moral style of teachers, and train socialist builders and successors for the all-round development of moral, intellectual, physical, aesthetic and labor.

We should improve the mechanism of family social co-education in school, improve the teaching ability of teachers, enhance the students' civilization, social responsibility, practice ability, attach great importance to the physical and mental health education of teenagers. The civilization and physical qualities of young people are increasingly valued by the state and society[2-4].

In order to construct a comprehensive education system for moral, intellectual, physical, aesthetic and labor, and to form a higher-level talent training system, the "Consideration on Strengthening Labor Education in the New Era" issued by the Central Committee of the Communist Party of China and the State Council in 2020[1].

It is pointed out in the opinion that labor education is a new demand of education by the New Age Party, an important content of the socialist education system with Chinese characteristics, an important component of the overall development of education system, and an educational activity that must be carried out in primary and secondary schools. It is very necessary to develop a series of labor education courses to meet the needs of local universities and colleges.

\section{LITERATURE REVIEW}

Liu Yang (2020) points out that for college students, on the one hand, college students can be combined with their specialized knowledge through labor education so that students can understand it deeply in practice[5]. On the other hand, through the course of labor education, the students of today's university will be able to face life independently and experience life-labour trivialities.

Noh Hyo-dong (2020) pointed out that labor education is not simply about labor, but about the need for action as well as brain washing[6]. Lu Xiaodong (2020) pointed out that the reason why labor education is called education is not simple labor, but because labor education requires both hands-on and brain[7].

Wang Li-rong (2020) pointed out that university students have a historical mission to realize the great rejuvenation of China's national dream, the perfection of the socialist education system of Chinese characteristics in the new era, and the future direction of the new generation in the plastic age[8].

Second, some scholars proposed the development of labor education courses based on local characteristics. In recent years, the city of Qinhuangdao, based on the principle of "innovation, coordination, greenness, openness and sharing", is based on the resource advantage of the hometown, and carries the students out of class, out of school, village and community.

In recent years, many local schools have been set up in different places to cater for the needs of schools and the needs of agriculture, but some have deviated from the original aims of labor education. One is that the aims of labor education are ambiguous.

The essence of labor education is to cultivate the students' love for and respect for labor and to form good working habits and correct values, not just to accomplish their credits or tasks. Second, labor practices lack a sense of place. It is only by putting teenagers on the labor scene that the meaning of labor education can be realized, not by relying on some of the materials of other people's labor.

Third, labor education is not a good combination of school and family. Young people's working habits require school education, and they need to be nurtured in their families. Fourth, the evaluation of labor education curriculum does not form a scientific system.

At present, the evaluation of labor education is based on the traditional evaluation method, but not on the basis of the goals of labor education, setting the standard for evaluating labor literacy and using modern information technology such as big data, 
cloud platform and Internet of Things[9-10].

The construction of the labor education curriculum is a very complex system project for construction of Double-Class Universities, which includes various factors such as goals, curricula, content, implementation and evaluation.

The curriculum design of labor education needs to balance the students of each section of primary and secondary schools to construct the relationship between man and himself, man and nature, man and society. Work hard to integrate labor education curriculum and teaching.

\section{METHODS}

To carry out a survey on the implementation of the course plan, to conduct questionnaires and interviews with college students, teachers and parents, to listen to the opinions and suggestions of teachers and students on the labor education curriculum, and to analyze the results of the results of the survey using statistical software such as SPSS/Spotfire/Stata[11].

\section{RESULTS}

Schools should formulate feasible teaching plans for labor education, arrange special full-time teachers, draw up credits, ensure the hours and course contents of labor education, and integrate them with other subjects in an organic way, find relevant knowledge in each subject and develop the work education curriculum group.

The main places of labor education are to develop labor education curriculum resources in classrooms and schools, excavate labor education resources contained in various subjects, and it is impossible to leave the curriculum to discuss labor education.

In the aspect of curriculum construction, we should cooperate in the relationship between compulsory and elective labour education, internal and external, classroom and extracurricular, formal and informal, direct and indirect.

The curriculum of labour education should cover various fields of science and technology, occupation, family administration, economy and law, and should keep pace with the development of society and be coordinated with the industrial revolution, the information revolution and the changes of life so that young people can think independently and use information and data analysis.

It is necessary to add crisis management related courses while developing labor education courses. Since adolescents' health is the most important thing, they should be able to learn about crisis management and use it in the course of crisis management. For example, recent disasters such as new crown pneumonia and floods in the South are important for young people to learn how to respond and protect them in advance.

\section{Conclusion}

The forms of labour education can be varied. It can be either collective labor study conducted in schools, individual labor study at home and in society, or labor education in the form of research travel.

In terms of educational methods, it is necessary to track the future technology, the future society's innovative labor form, bring together innovation and creativity, introduce Internet + labor education, artificial intelligence + labor education.

According to the goals of labor education, set up the standard for evaluating labor literacy and make use of modern information technology such as big data, cloud platform and Internet of Things.

It includes evaluation of the organization of the course, arrangement of the teaching content, determination of the duration and credit of the course, and planning of the course's development for the construction of Double-Class Universities.

First, Schools should make feasible teaching plans for labor education, arrange special full-time teachers, draw up credits, ensure the class hours and curriculum content of labor education, organically combine with other disciplines, find out the relevant knowledge of various disciplines, and develop the curriculum group of labor education.

The main position of labor education is in the classroom. It is impossible for schools to develop the curriculum resources of labor education and excavate the labor education resources contained in various disciplines without curriculum.

Second, In the aspect of curriculum construction, we should coordinate the relationship between compulsory and optional labor education, inside and outside school, inside and outside class, formal and informal, direct and indirect.

Labor education curriculum should involve science and technology, occupation, home economics, economy, law and other fields, and keep up with the pace of social development, and coordinate with the industrial revolution, information revolution and life change, so that young people can have the ability to think independently and use information and data analysis.

Third, At the same time of developing labor education curriculum, crisis management related curriculum should be added. As the physical health of teenagers is the most important, we should let teenagers learn the professional knowledge of crisis management and apply these knowledge to the 
process of crisis drills, so as to really prevent the crisis.

For example, novel coronavirus pneumonia and flood in the south, and so on, how to make the young people take the lead and make a good response and protection in advance is very important.

Fourth, In the construction of labor education curriculum, according to the national conditions and education development situation of our country, we can reasonably learn from the successful experience of other countries on the construction of labor education curriculum.

The connotation of labor education in different countries is different, the value orientation of labor education is different, and the implementation ways of labor education have their own characteristics.

In the new era, China adheres to the basic red line of labor education, and learns from the successful experience of foreign countries, so as to better form a labor education curriculum system with its own national characteristics that can help teenagers develop in an all-round way.

Fifth, We should pay attention to the labor differences of students under different living backgrounds in rural or central urban areas, and take into account the proportion of daily life labor, service labor and production labor in different periods. We should persist in adjusting measures to local conditions, based on reality, and carry out labor education in combination with local natural, economic and cultural conditions.

Sixth, The forms of labor education can be various. It can be collective labor learning in school, individual labor learning in home and society, and labor education in the form of research and study travel.

In terms of education, we should track the future innovative technology and the form of innovative labor in the future, integrate innovation and creativity, and introduce Internet plus labor education, artificial intelligence + labor education.

Seventh, According to the goal of labor education, we should formulate the evaluation standard of labor literacy and make a scientific evaluation by using big data, cloud platform, Internet of things and other modern information technology.

It includes the organization form of the evaluation course, the arrangement of the teaching content, the determination of the class hours and credits of the course, and the plan of the course development.

\section{REFERENCES}

[1] Jialei, J., \& Eun-Mi, P. (2021). An Analysis of the Equity of Students' Investment Base on Korea Local Education
Finance. International Journal of Emerging Multidisciplinary Research(IJEMR), 5(1), 8-13.

[2] Mun, S.B.(2012). An Analysis of Equity in Korean Education Based on OECD International Indicators: Focusing on Comparisons between Cities and Provinces, Korean Educational Development Institute.

[3] Wu Zhenying. (2011). Research on reasonable calculation scheme of per capita education expenses of students. Master's thesis.Myongyi University.

[4] Odden, A. R. \&picus, L. O. (2007). School Fiance: A Policy Perspective (4thed.). NY: McGraw-Hill.

[5] Wang Li-rong. (2020). On the Value Implication of Labor Education for College Students in the New Age. Journal of Higher Education Exploration, 2020(7), 114-118.

[6] Liu Yang(2020). A Study on the Construction of the Ecological System of Labor Education in the New Age of Local University. Journal of China Steel Focus, 2020(7),190-191

[7] Noh Hyo-dong (2020). Key to the Framework, Characteristics and Implementation of the University's Labour Education Curriculum: theoretical field of vision based on labor elements. Journal of China University Teaching,2020(2-3),8-16

[8] Lu Xiaodong, Qu Xia(2020). Curriculum framework, characteristics and implementation key of University Labor Education: a theoretical perspective based on labor factors [J]. China University teaching, 2020 (2-3): 8-16

[9] Park, S. T., \& Liu, C. (2020). A study on topic models using LDA and Word2Vec in travel route recommendation: focus on convergence travel and tours reviews. Personal and Ubiquitous Computing, 1-17.

[10] Park, S. T., Li, G., \& Hong, J. C. (2020). A study on smart factory-based ambient intelligence context-aware intrusion detection system using machine learning. Journal of Ambient Intelligence and Humanized Computing, 11(4), 1405-1412.

[11] Jiang, J., Park, E. M., \& Park, S. T. (2021). The Impact of the COVID-19 on Economic Sustainability - A Case Study of Fluctuation in Stock Prices for China and South Korea. Sustainability, 13(12), 6642. 